\title{
Experiencia de redacción autorregulada y retroalimentada en la recomendación de textos literarios en bachillerato
}

\author{
Experience of Self-Regulated Writing with Feedback in the \\ Recommendation of Literary Texts in High School
}

\author{
Experiência de redação autorregulada e retroalimentada na \\ recomendação de textos literários na educação média
}

Ernesto Hernández-Rodríguez ${ }^{1}$

\section{Resumen}

Este artículo de investigación presenta la aplicación de una propuesta de actividades escolares para propiciar la autorregulación de la intencionalidad y el desempeño escrito en el marco de los estudios de textualidad. Un grupo de 32 estudiantes de nivel medio superior de la Escuela Nacional Preparatoria participó en actividades para recomendar por escrito un texto literario. La propuesta de experiencias de escritura incluyó la toma de acuerdos sobre las características de la recomendación escrita. Los estudiantes valoraron sus propios textos y los de otros alumnos y, a partir de la revisión y de distintos tipos de retroalimentación, intentaron escribir una segunda versión mejorada. El trabajo incluye ejemplos de las actividades y la caracterización de la intencionalidad y el desempeño textual cuando los estudiantes trataron de mejorar los contenidos, la representación textual de los alumnos y de los interlocutores, y los recursos para opinar y recomendar el texto seleccionado. Los resultados muestran que la toma de acuerdos y la reflexión sobre el desempeño y las prácticas de textualidad favorecen la redacción. Sin embargo, el avance en la intencionalidad y el desempeño se aprecia en la práctica retroalimentada de revisión y edición textual. Así los estudiantes lograron tomar decisiones y autorregular sus desempeños.

\section{Palabras clave}

redacción; revisión; edición; autorregulación; intencionalidad

\section{Abstract}

This research paper presents the implementation of a proposal of school activities to promote the self-regulation of intentionality and written performance within the framework of textuality studies. A group of 32 students from Escuela Nacional Preparatoria participated in a series of activities to recommend a literary text in writing. The proposal of writing experiences included making agreements on the characteristics of the written recommendation. The students evaluated their own texts and those of other students and, based on the review and on different types of feedback, they attempted to write a second, improved version. The work includes examples of activities and the characterization of intentionality and textual performance when students tried to improve content, the textual representation of the students and the audience, as well as the resources to comment and recommend the selected text. Results show that making agreements and reflecting on the performance and the practices of textuality do favor writing. However, the progress made in intentionality and performance is seen in the feedback practice of revision and editing of the texts. Thus, students were able to make decisions and self-regulate their performance.

\section{Keywords}

writing; revising; editing; self-regulation; intentionality

1 Doctor en Humanidades en la línea de Lingüística. Profesor asignatura de Literatura, Escuela Nacional Preparatoria, Universidad Nacional Autónoma de México, Ciudad de México. Corro electrónico: ernestohero@comunidad.unam.mx 


\section{Resumo}

Este artigo de pesquisa apresenta a aplicação de uma proposta de atividades escolares para propiciar a auto-regulação da intencionalidade e o desempenho escrito no âmbito dos estudos de textualidade. Um grupo de 32 estudantes de nível médio superior da Escola Nacional Preparatória participou em atividades para recomendar, por escrito, um texto literário. A proposta de experiências de escrita incluiu os acordos realizados sobre as características da recomendação. Os estudantes avaliaram seus próprios textos e os de outros alunos e, a partir da revisão e de diversos tipos de acompanhamento, tentaram escrever uma segunda versão melhorada. 0 trabalho inclui exemplos das atividades e a caracterização da intencionalidade e o desempenho textual quando os estudantes tentaram melhorar os conteúdos, a representação textual dos alunos e dos interlocutores, e os recursos para opinar e recomendar o texto selecionado. Os resultados evidenciam que os acordos e a reflexão sobre o desempenho e as práticas de textualidade favorecem a redação. Porém o avanço na intencionalidade e o desempenho é apreciado na prática acompanhada de revisão e edição textual. Assim os estudantes conseguiram tomar decisões e autorregular seu desempenho.

\section{Palavras chave}

redação; revisão; edição; autorregulação; intencionalidade

\section{Artículo recibido el 11 de enero de 2017 y aprobado el 28 de julio de 2017}

\section{Introducción}

En las asignaturas de lengua, en general, los estudiantes de bachillerato experimentan dificultades para comentar y recomendar por escrito una lectura. En la práctica nos percatarnos de que intentan hacerlo mediante sus propios hábitos, recursos y consideraciones textuales, por ejemplo, a manera de resumen o relatando pasajes de la lectura, y por ello se ven en la necesidad de modificar su desempeño lingüístico para responder a las expectativas de desempeño escolar. La apropiación de los recursos de redacción y el manejo de los géneros textuales requiere de un proceso gradual de aprendizaje. Podemos encontrar este interés por el desarrollo de la escritura en actividades en el aula, por ejemplo, en Carlino (2004), Zavala (2009), Camps (2009) y Hernández-Rodríguez (2015). Para la redacción no es suficiente conocer reglas de escritura y seguir modelos impuestos para emplear determinado género textual, ya que quienes escriben y quienes leen un texto ponen en juego estándares de textualidad (De Beugrande y Dressler, 1997) correspondientes a criterios y consideraciones sobre la escritura que involucran, además de la estructuración textual, las expectativas y valoraciones de intencionalidad, adecuación y situacionalidad del texto redactado. Las prácticas descontextualizadas de escritura no les resultan significativas a los estudiantes porque no representan experiencias que permitan la modificación de conocimientos y hábitos lingüísticos. Por ello, es fundamental diseñar experiencias de escritura que fomenten el desarrollo integral de la redacción retroalimentada para propiciar la autorregulación reflexiva del desempeño lingüístico.

En el marco de la lingüística textual, encontramos estudios que abordan la reflexión sobre la redacción; por ejemplo, Hyland (2005) considera las prácticas de representación textual del autor y los interlocutores. Esta propuesta es de utilidad para la toma de conciencia de los recursos textuales que requieren los estudiantes al comentar una lectura. Asimismo, Adam (2004) tiene en cuenta los recursos y relaciones de estructuración intra- y extratextuales en el proceso de escritura, así como categorías para describir y analizar los textos. Este enfoque es relevante para analizar el desempeño escrito de los estudiantes en la perspectiva de la lingüística textual. Además de caracterizar los recursos de escritura, es fundamental el diseño de actividades para mejorar la redacción, en este caso, al recomendar textos literarios, a partir de un aprendizaje reflexivo e interactivo que permita la autorregulación del desempeño en la revisión y edición de los textos.

El propósito de este trabajo es conocer los resultados de la aplicación de una propuesta de actividades encaminadas a favorecer la autorregulación de la intencionalidad y el desempeño en la redacción de recomendaciones de textos literarios mediante prácticas reflexivas de revisión y edición textual en un curso de literatura mexicana en bachillerato. La caracterización del desempeño contempla categorías correspondientes a recursos de escritura 
relacionados con los estándares de textualidad en los intentos de los estudiantes por tratar de mejorar la redacción en una segunda versión.

La propuesta contempla la revisión de los textos propios y de otros para reflexionar sobre recursos y estrategias de escritura y valorar el desempeño. Los acuerdos sobre la recomendación escrita de un texto permiten establecer criterios socializados para regular y valorar el desempeño en las prácticas de revisión y edición textual. La retroalimentación y las sugerencias recibidas tienen el propósito de apoyar a los alumnos en la resolución las dificultades enfrentadas, con la idea de mejorar las recomendaciones redactadas.

El énfasis en las actividades está en la experimentación, la reflexión y la autorregulación del desempeño en prácticas que se pueden aplicar en distintas asignaturas. La propuesta no es un plan de clases, ni una secuencia didáctica preestablecida; cada docente puede modificar y adaptar las actividades conforme a diversas necesidades, tiempos, contenidos y contextos.

\section{Enfoque}

En este trabajo contemplo la caracterización de la intencionalidad en el desempeño. Beuchot (2015) destaca que lo que alguien expresa no siempre corresponde a lo que realmente intentó comunicar. Los estudiantes enfrentan dificultades para plasmar sus ideas por escrito. En ocasiones la intencionalidad expresada corresponde a manifestaciones parcial o totalmente alejadas de lo que escriben. Por ello, se justifica el diseño de experiencias encaminadas a la reflexión y la toma de conciencia sobre el manejo de recursos de escritura y la autorregulación del desempeño en la revisión y edición para tratar de mejorar los textos. Torre-Puente (1992) propone que "enseñar a preguntarse, a autovigilarse, a analizar el fallo en los hábitos comportamentales, a detenerse y a analizar qué es lo que se está haciendo, es el punto de partida para la consecución de la autorregulación" (p. 55). Por otra parte, con el propósito de relacionar los conocimientos de los estudiantes sobre el proceso de la redacción y las maneras de autorregular el desempeño escrito en la coherencia y la productividad, Bausela-Herreras (2007) plantea la toma de conciencia de las habilidades, los estilos de aprender y la autorregulación del desempeño lingüístico.

Castelló, Bañales-Faz y Vega-López (2010) contemplan un panorama de prácticas de autorregulación que involucra las perspectivas cognitiva, sociocognitiva y sociocultural. De esta forma, podemos advertir que la diversidad de prácticas de autorregulación del desempeño lingüístico no se limita al nivel de conocimientos y habilidades de textualización, ya que la interacción contextualizada cumple un papel fundamental. La autorregulación del desempeño se manifiesta en las decisiones de revisión y edición de la escritura y en la toma de conciencia de la intencionalidad en los recursos y estrategias de redacción como resultado de la socialización de la comunicación contextualizada. Así, los estudiantes pueden evaluar sus escritos para determinar si deben modificarlos para mejorarlos conforme a la intencionalidad deseada.

De Beugrande y Dressler (1997) plantean que los estándares de textualidad son las consideraciones, los conocimientos y las expectativas que autores y lectores tenemos sobre un texto en la comunicación: cohesión, coherencia, intencionalidad, informatividad, situacionalidad, aceptabilidad e intertextualidad. La cohesión está conformada por los elementos formales empleados en la construcción gramatical y en la estructura textual, la coherencia es el manejo de las ideas en mensajes entendibles y con sentidos claros. La intencionalidad pone de manifiesto aquello que quien escribe desea expresar, aun cuando no siempre lo logre. La informatividad se relaciona con el manejo de la diversidad de contenidos empleados en la comunicación. La situacionalidad es el uso del lenguaje en determinada situación y contexto. La aceptabilidad es el conjunto de criterios de uso social empleados para determinar la pertinencia de lo expresado en determinado género y práctica comunicativa, y la intertextualidad es el establecimiento de relaciones implícitas y explícitas entre los elementos de significado dentro de un texto, así como con otras fuentes textuales externas. 
La variedad de textos, formatos, soportes, repertorios, géneros y posibilidades comunicativas constituye la textualidad en la comunicación. Las prácticas de textualización son los manejos de recursos lingüísticos, contextuales y de estándares de textualidad que empleamos al regular nuestro desempeño escrito. Hyland (2005) estudia las consideraciones reflexivas de quien escribe al intentar representarse a sí mismo en el texto y a los interlocutores. Además, los estudiantes requieren tomar decisiones sobre el tipo de texto para determinada situación comunicativa. Bajtín (1982), Van Dijk (1983) y Adam (2004) consideran la intencionalidad en la decisión del género textual y el problema de definir los géneros textuales, por ejemplo, en términos de la clasificación textual, la influencia discursiva y de marcas textuales (Charadeau, 2004; Eggins y Martin, 2003) y el contexto comunicativo (Ciapuscio, 2015).

Las propuestas de Oxford (1990), Martín Leralta (2006) y Palapanidí (2016) sobre el desarrollo de estrategias alternativas o compensatorias de aprendizaje propician que los estudiantes tomen decisiones de textualización con base en la reflexión sobre la intencionalidad y la autorregulación del desempeño, tal como proponen Wenden (1986) y Dickinson (1987). La idea es lograr la toma de conciencia gradual sobre los recursos de escritura relacionados con los estándares de textualidad, el tipo de texto y la representación de interlocutores.

Este trabajo involucra actividades de discusión sobre consideraciones, conocimientos y expectativas de una recomendación escrita, así como la experiencia de recibir comentarios y sugerencias sobre el desempeño, y valorarlos conforme a acuerdos socializados, de manera tal que sean de utilidad para las decisiones reflexivas de revisión y edición con la idea de mejorar la redacción.

\section{Los alumnos y los textos recomendados}

Apliqué este diseño de actividades en septiembre de 2015 con alumnos de un promedio de 17 años de edad de tercer ciclo vespertino de la Escuela Nacional Preparatoria, plantel 3 de la Universidad Nacional
Autónoma de México, al norte de la Ciudad de México. Los estudiantes cursaban el último año de Educación Media Superior en el área de disciplinas químico-biológicas. La asignatura de literatura es parte de las materias curriculares. Los alumnos presentaban un desempeño y una asistencia regular. Para ingresar a esta institución es necesario obtener un promedio alto en el examen de admisión y mantenerlo para aspirar a la educación superior.

Los estudiantes seleccionaron una lectura del curso para recomendarla por escrito. Previamente leímos parte de los textos en clase, los comentamos y ellos tenían que concluir las lecturas en casa. Les insistí en que escogieran el texto que mejor habían comprendido. Las lecturas forman parte del inicio del curso de Literatura Prehispánica y presentan temáticas mitológicas de la tradición oral, expresada por informantes y por las pinturas en códices, transcritos y traducidos al español en el siglo XVI. Las lecturas corresponden a la antología de LeónPortilla (2003) y al "Lenguaje de Zuyua" en la versión del Chilam Balam presentada por Barrera-Vázquez y Rendón (1983). En el anexo 1 se presenta el contenido de las lecturas.

\section{Diseño y metodología de las actividades realizadas}

\section{Consideraciones sobre la recomendación escrita y los acuerdos para su redacción}

El propósito era que los alumnos expresaran sus percepciones sobre las características textuales de la recomendación de una lectura y, además, que escribieran una primera versión con los recursos y conocimientos textuales contemplados en los acuerdos tomados en la primera sesión. A partir de la revisión y edición de la primera versión, tendrían elementos para desarrollar y autorregular su desempeño, tal como plantean Wenden (1986) y Dickinson (1987). De este modo, evitamos imponer modelos rígidos de escritura, al propiciar la reflexión sobre el desempeño propio y las características del texto para recomendar. Cada alumno expresó por qué le interesaba la lectura, conforme a la guía de apoyo que se muestra en el cuadro 1. 
Cuadro 1. Guía de apoyo

Lectura seleccionada para comentar y recomendar.

¿Qué aspectos de la lectura te

interesan? Menciona algunos.

Puedes elegir alguno o algunos de estos aspectos para escribir tus comentarios y la recomendación de la lectura.

¿Cuáles abordarás en tu escrito?

¿Por qué te interesa comentar y recomendar esta lectura?

Era fundamental tomar en cuenta las ideas de los estudiantes sobre las características de una recomendación escrita, y por ello contemplé sus consideraciones sobre cómo debe estar escrito un texto para comentar una lectura a partir de la siguiente pregunta:

¿Qué características consideras que debe tener un texto para recomendar una lectura de tu interés?

Los alumnos participaron en una lluvia de ideas. De esta forma podríamos tener elementos para contemplar la información, socializarla y llegar a acuerdos. Apunté en el pizarrón el siguiente listado de sus opiniones sobre las características de una recomendación:

Breve, concreto, al tema, llamativo, no contar de más para no desanimar al lector, destacar aspectos relevantes, lenguaje sencillo, informar sobre el título, autor y época, legible, coherente, cuidar gramática y ortografía, tener introducción y citas textuales.

Al terminar, comentaron las características de una recomendación escrita. Les dije: "Vamos a ponernos de acuerdo sobre cómo deben estar escritos estos textos". Finalmente, entre todos negociamos los siguientes acuerdos:

- Presentar información adecuada: la necesaria, no contar de más, ni el final.

- Mencionar datos sobre la lectura: título, autor, época.

- Expresar una opinión clara, puntos de vista.

- Tomar en cuenta al lector: dirigirnos a él para atraerlo.
- Presentar ejemplos para tratar de animar al lector.

- Ser breve e interesante.

- Escribir un texto coherente y gramaticalmente cuidado.

Enseguida escribieron los pasos que seguirían para la recomendación, las partes del texto y cómo lo iban a organizar. Así, podrían reflexionar sobre su desempeño en una versión que sería modificada posteriormente. Revisemos las instrucciones:

\section{¿Cómo vas a organizar tu escrito para expresar tus ideas y recomendar la lectura? \\ Menciona las partes del texto que escribirás: ¿Cómo vas a empezar y a continuar?}

Después escribieron sus recomendaciones, que continuaron la siguiente sesión.

Ahora escribe el texto en el que comentes y recomiendes la lectura de tu interés para que otras personas se animen a leerla.

\section{Compartir y revisar el texto propio}

El propósito de estas actividades era experimentar distintos tipos de retroalimentación para promover la reflexión sobre el desempeño relacionado con los estándares de textualidad (De Beugrande y Dressler 1997): cohesión, coherencia, intencionalidad, informatividad, intertextualidad, situacionalidad y aceptabilidad. Así, los estudiantes tuvieron oportunidad de valorar las características de un escrito en una función, una situación y un contexto comunicativo. La retroalimentación incluyó recibir comentarios escritos del docente y de un conocido del alumno, así como la revisión con el corrector ortográfico y gramatical del procesador de textos Word.

Les solicité que, de tarea, compartieran sus escritos con alguien que no conociera la lectura recomendada, por ejemplo, un familiar, un amigo u otra persona de confianza que les hiciera observaciones y comentarios. Revisemos las instrucciones:

Comparte tu escrito con alguien de confianza que nunca haya leído el texto que recomendaste. Pídele 
una opinión sobre tu escrito. Pregúntale si le quedó claro lo que expresaste y si se animaría a leer el texto que recomendaste.

A continuación escribe lo que te comentó esta persona.

¿Crees que su opinión te puede servir para mejorar tu escrito? Sí No ¿Por qué?

Además, les pedí a los alumnos que revisaran sus escritos con un procesador de textos.

Teclea tu texto en la computadora con el programa Word. Revisa tu escrito con el corrector gramaticaly ortográfico. Realiza las correcciones que consideres necesarias.

¿Crees que las observaciones que indica el programa de revisión y corrección Word te pueden servir para mejorar tu escrito?

Sí No ¿Por qué?

Posteriormente comentamos la experiencia de retroalimentación recibida y la revisión con el corrector ortográfico y gramatical del procesador Word. Platicamos sobre cómo les podría servir esta práctica.

Comenta con tu profesor los comentarios que recibiste sobre tu escrito y el resultado de la revisión ortográfica y gramatical con el programa Word. Reflexionen juntos si estas prácticas te pueden ayudar a mejorar tu escrito en una segunda versión.

A continuación, toma nota de lo que comentaron tú y tu profesor sobre tu escrito.

En las siguientes tres sesiones orienté a los estudiantes sobre el tipo de texto requerido, sus características y los recursos de lenguaje necesarios para recomendar una lectura.

Recuerda. Tu texto no es un resumen ni se trata de que solo cuentes o relates el libro. Es un escrito en el que comentas y recomiendas la lectura que seleccionaste. Revisa tu escrito y fijate si en realidad comentas y recomiendas el texto para que otros se animen a leerlo.

Asimismo, los asesoré sobre la representación del autor, los interlocutores y el contenido. Por ejemplo:
Es conveniente que expreses tu opinión en primera persona del singular (yo), puesto que se trata de tu propia opinión, lo que tú piensas.

Toma en cuenta a quienes van a leer tu escrito. Puedes dirigirte directamente a tus lectores para tratar de convencerlos.

No cuentes toda la historia porque si escribes información de más, las personas perderán el interés.

Este tipo de asesoría implica un apoyo gradual para la toma de conciencia acerca del tipo de texto requerido y la manera de tomar en cuenta a los lectores desde un posicionamiento textual como autor, así como los recursos textuales para lograr esta práctica de escritura (Hyland, 2005).

\section{Comentar el desempeño de otros}

En otra sesión, les pedí a los alumnos que comentaran el desempeño de otros estudiantes desconocidos, quienes recomendaron lecturas por escrito. La idea era que tuvieran una primera experiencia de identificación y valoración de elementos de textualidad en un texto distinto al propio, de forma que se sintieran libres para hacer observaciones y valoraciones con respecto a la escritura.

A continuación leerás un texto de un estudiante que comentó y recomendó a otras personas un cuento de su interés. Después de leerlo, comenta con otros compañeros la manera en que está escrito.

¿Te queda claro el contenido de la lectura comentada $y$ recomendada?

¿El escrito te motiva a leer ese cuento? ¿Por qué?

Seleccioné dos recomendaciones de alumnos anónimos de tercer semestre, quienes comentaron el cuento "La bella durmiente del bosque" de Perrault (2006). La brevedad del texto nos permitió leerlo en la clase y así los alumnos tuvieron más elementos para discutir el desempeño de quienes escribieron las recomendaciones. En la primera de ellas, a pesar de algunas dificultades de acentuación y segmentación de palabras, la autora anónima se esforzó y mostró avance en el desempeño, puesto que informó sobre el contenido, representó a los lectores y trató de atraerlos y convencerlos (véase el anexo 2). 
También consideré conveniente comentar un texto con un mayor número de dificultades de redacción no resueltas, puesto que este tipo de textos puede propiciar distintos comentarios sobre cómo mejorarlos. En la recomendación 2 del texto de Perrault faltaba información y comentarios sobre el cuento. El autor solo enfatizó su impresión de gusto y mencionó el amor del príncipe y la princesa (véase el anexo 3).

Con tu profesor leerás el cuento que el estudiante recomendó.

Ahora que leíste este cuento, escribe una opinión sobre la manera en que el estudiante lo comentó y recomendó.

¿Qué sugerencias le harías para mejorar su texto?

Los alumnos comentaron los textos e hicieron sugerencias para mejorar las recomendaciones.

\section{Escribir textos representativos}

En la siguiente clase, en grupos de tres o cuatro, los estudiantes escribieron recomendaciones de alguna de las lecturas del curso. El propósito era discutir y socializar los acuerdos para reflexionar, negociar y tomar decisiones de redacción, revisión y edición en equipo.

En la siguiente actividad, entre todos contemplamos los acuerdos y escribimos la recomendación de una lectura. Finalmente, los alumnos contemplaron las experiencias para revisar, corregir y editar sus propios escritos en las segundas versiones mejoradas.

Haz tu mejor esfuerzo para escribir la versión mejorada de tu texto para comentar y recomendar la lectura. La propuesta es que compartas tu escrito en la comunidad escolar por medio del blog de la preparatoria. Para ello tendrás que revisar $y$ corregir tu texto hasta que quede listo. Para ayudarte, toma en cuenta lo que aprendiste en todas las experiencias de este ejercicio.

En las asesorías para la revisión y edición del escrito en una segunda versión, retomé los acuerdos y las experiencias de escritura y reflexión sobre el desempeño propio y de otros como elementos para favorecer la autorregulación del desempeño en las decisiones para tratar de mejorar la redacción.

\section{Resultados}

\section{Sobre las actividades de apoyo a la redacción}

El propósito de las actividades de apoyo era que los estudiantes experimentaran distintas prácticas de sensibilización y reflexión sobre la manera de organizar y planear la recomendación del texto literario, así como distintas posibilidades de retroalimentación sobre el desempeño. Esta sección presenta ejemplos representativos de las consideraciones de los estudiantes sobre los aspectos contemplados en las actividades realizadas, así como las actitudes y reacciones ante una primera retroalimentación relacionada con los comentarios recibidos por alguien de confianza y mediante el procesador de textos Word.

Los alumnos expresaron los procedimientos que llevarían a cabo en la redacción, las partes del comentario y la manera de organizar la escritura, tal como podemos ver en el siguiente ejemplo.

Ejemplo 1: texto $11 \mathrm{~m}$

Voy a poner el título, después una breve introducción de la historia, de qué trata, sin decir de más, poner que va a tener algunos problemas, sin embargo no contar cuales, escribir sobre los personajes relevantes, $\mathrm{y}$ al final poner mi opinión sobre esta y la forma en la que fue escrita, poner el porqué la recomiendo.

Como resultado de la primera retroalimentación sobre sus recomendaciones, por parte de personas que no conocían la lectura recomendada, los estudiantes pudieron valorar las observaciones sobre sus propios escritos. Esta práctica les sirvió para autorregular su desempeño al intentar una segunda versión mejorada. A continuación presento dos ejemplos representativos de la retroalimentación recibida.

Ejemplo 2: texto $7 \mathrm{~m}$

Solo me quedan 2 preguntas: “ $¿ E l$ lenguaje de Zuyua es un libro maya?, y ¿Quiénes son los 
Halach Uiniques? De ahí en fuera sí se entiende. Y sí te invita a leer el libro, o bueno, te genera curiosidad por saber cuál es la respuesta”.

Opinión de la alumna sobre estos comentarios: Sí, porque me ayuda a darme cuenta en donde queda duda sobre mi recomendación y que al menos logré incitar a la persona a que leyera el texto.

Ejemplo 3: texto $19 \mathrm{~m}$

No sé si me animaría a leerlo ya que no me explica del todo bien sobre el principal argumento del texto.

Opinión del alumno sobre estos comentarios: Me sirve porque cada opinión que dan a mi recomendación es porque son puntos de vista sobre algunas fallas que tiene la recomendación.

En cuanto a la opinión sobre los comentarios recibidos, a 29 estudiantes les parecieron de utilidad y 3 respondieron que no les servían (textos 4,10 , 13). Podemos advertir la disposición para recibir comentarios sobre el desempeño. Revisemos algunas de las impresiones.

Ejemplo 4: texto $13 \mathrm{~m}$

No. Porque nada más me dijo que estaba breve pero se supone que escrito así debe ser breve.

Ejemplo 5: texto26h

Sí. Hizo una crítica constructiva a mi trabajo, me dio una idea o varias para mejorar mi redacción y me animó al decirme que tenía ganas de leerlo.

Sobre la revisión de la escritura con el procesador de textos Word, en su mayoría los estudiantes consideraron que el corrector ortográfico y gramatical es útil, solo 7 dijeron lo contrario (textos $7,14,16,20$, $25,30,31)$. En general, tomaron en cuenta las ventajas de esta herramienta, así como las limitaciones y la necesidad de contextualizar su uso en la práctica.

Ejemplo 6: texto $15 \mathrm{~m}$

Sí. Porque tenía errores ortográficos y Word me ayudó. Gramaticalmente no me ayudó mucho aún le falta mucho un poco más de corrección. Si me sirven para mejorar mi ortografía.

Ejemplo 7: texto 25h
No. Word puede corregir cosas sencillas como acentos, pero es porque tiene agregado en su diccionario la mayoría de las palabras que usamos, pero si no la conoce me podría confundir la palabra con otras que se le parezca o si la escribí mal y no la tiene agregada no podrá advertírmelo. Además hay muchos errores ortográficos que el programa Word no detecta como el uso correcto de las comas, punto y coma etc. Solo serviría en casos menores.

Estas actividades favorecieron la reflexión sobre prácticas relacionadas con los estándares de textualidad (De Beugrande y Dressler, 1997), la reflexión metadiscursiva en la representación de interlocutores (Hyland, 2005) y el manejo del género textual (Bajtín, 1982 y Ciapuscio, 2015). También ayudaron a autorregular el desempeño, tal como propone Wenden (1986) y en el enfoque de Oxford (1990), contribuyen al desarrollo de estrategias de aprendizaje.

La práctica de opinar sobre el desempeño escrito de estudiantes anónimos que recomendaron el cuento de Perrault (2006) sirvió para formar criterios acerca de diversos recursos y estilos de escritura. Los estudiantes se sensibilizaron con relación a estrategias de redacción que posteriormente podían emplear al valorar y regular su propio desempeño. De manera predominante, 21 alumnos consideraron que la recomendación 1 era la más cercana a los acuerdos alcanzados, 6 dijeron que estaba bien pero criticaron que contara el final del cuento, 3 dijeron que el texto 2 era el adecuado y 2 que ninguno. En los siguientes ejemplos los alumnos destacan criterios de informatividad en el manejo de contenidos.

Ejemplo 8: texto $11 \mathrm{~m}$

Recomendación 1: Creo que su idea era la adecuada, si me causa curiosidad hasta cierto punto, pero el estudiante, puso de más, cuenta el final, y formula una interrogación que te da una idea del problema, da información innecesaria, que te hace perder las ganas de leerla. Sugerencias: Que no cuente el final, ni el clímax, que en este caso sería la pregunta “¿Y tú qué harías si te comiera tu suegra?" se abstenga de contar partes fundamentales de la historia. 
Recomendación 2: La recomendación es muy corta, demasiado, y no habla sobre la historia, sino solo la opinión del estudiante, no me intrigó la historia. Sugerencias: No decirlo de manera expositiva, tomar en cuenta al lector, agregar más información, para que al lector le intrigue la historia y lo convenza.

Ejemplo 9: texto 22h

Recomendación 1: La manera en la que la recomienda no es del todo bien, ya que narra todo lo que sucedió con detalle acerca de la historia, dejando sin ganas de leer al lector. Sugerencias: No decir los acontecimientos de lo que ocurre ya que deja las ganas de leerla. No dar las vistas propias.

Recomendación 2: La manera en que la recomienda está bien ya que te dice lo que puedes encontrar en la lectura sin decir bien lo que sucede, hace que si de ganas de leerla. Sugerencias: Es una recomendación muy bien escrita ya que te dice lo que encontrarás en esa lectura y te deja con las ganas de leerla.

Podemos establecer que los estudiantes no estaban acostumbrados a comentar la escritura de otro conforme a los acuerdos establecidos. Por ejemplo, en el texto $22 \mathrm{~h}$, el estudiante considera que la recomendación 2 está "muy bien escrita", a pesar de que es una de las menos logradas. El ejercicio permite reflexionar sobre los acuerdos y cómo podría mejorarse el escrito, en un proceso gradual para aprender a valorar el desempeño de otros. Tal como considera Dickinson (1987), el aprendizaje autónomo pasa por una fase o estadio de semiautonomía, y por ello requerimos de un entrenamiento para hacer la transición hacia el aprendizaje autónomo. Conocer distintas clases de desempeño nos permite formar nuestros propios repertorios lingüísticos y desarrollar estrategias de aprendizaje.

En la práctica de escribir en grupo recomendaciones de alguna de las lecturas del curso, los estudiantes discutieron y socializaron los acuerdos para tomar decisiones de redacción, revisión y edición. En los siguientes ejemplos, podemos darnos cuenta del esfuerzo por tomar en cuenta los acuerdos.

Ejemplo 10: texto redactado en equipo
Es un texto del náhuatl de la época prehispánica, que relata la huida del rey Quetzalcóatl quien es intimidado por los tres magos quienes le traen un espejo con el símbolo de un conejo; Pero ¿Qué significa este conejo? ¿En qué crees que termina este confrontamiento del rey con los magos? ¿Qué desenlace se llevará a cabo? Me parece que es un texto interesante y lo recomiendo porque encontraras un lenguaje diferente y una situación de huida consecuencia de las 3ras personas.

¿Crees que los vicios te lleven a algo bueno?

La redacción grupal del comentario de una lectura del curso permitió a los alumnos retomar los criterios y negociar los acuerdos de redacción para tenerlos presentes en el proceso de redacción de sus propios escritos.

Ejemplo 11: texto redactado en grupo

¿Te imaginas cómo nace un Dios?

"Mucho honraban los Mexicas a Huitzilopochtli, sabían ellos que su origen, su principio fue de esta manera..., el fragmento anterior pertenece a un texto de México Prehispánico originalmente en Náhuatl en el libro de Cantos y Crónicas del México Antiguo recopilado por León Portilla.

Te invito a que descubras la historia de una diosa madre traicionada por sus propios hijos y la reacción del más valeroso de sus hijos. Te garantizo que este texto te despertará el gusto por la mitología prehispánica y del principal dios de los aztecas.

No te lo puedes perder.

Esta propuesta de redacción contempla -como plantean Brockett y Hiemstra (1991) y Birembaum (2002) - la capacidad de asimilar conocimiento y aplicarlo, la habilidad para pensar críticamente y poner en funcionamiento la autoevaluación, así como la comunicación y la colaboración con otros.

Estas actividades, previas a la recomendación escrita realizada individualmente, facilitan, conforme a lo planteado por Knowles (1975), el desarrollo de iniciativas, porque al considerar las experiencias propuestas, los estudiantes pueden desarrollar aprendizajes reflexivos y autodirigidos. Asimismo, diagnostican necesidades, metas de aprendizaje, identifican recursos, deciden, se autorregulan y autoevalúan. 


\section{El desempeño y la intencionalidad en las dos versiones}

En la caracterización de los textos considero las manifestaciones de intencionalidad y autorregulación del desempeño para intentar mejorar los escritos. En la presentación de resultados y ejemplos representativos de ambas versiones podemos observar distintos niveles de desempeño e intentos por resolver dificultades. Cada estudiante tomó decisiones de textualización conforme a las maneras en que las actividades desarrolladas antes de la escritura de cada versión impactaron en su desempeño. Por ello, en la asesoría insistí en retomar las reflexiones sobre los acuerdos relacionados con las características de las recomendaciones, los tipos de retroalimentación, las experiencias de revisión, la valoración de los escritos de otros y la redacción en equipo y grupal.

En este trabajo, la caracterización del desempeño se centra en los criterios acordados, con énfasis en los contenidos, relacionados con los estándares de informatividad e intertextualidad (De Beugrande y Dressler, 1997), las representaciones textuales de los lectores y del alumno, como autor, para opinar sobre la lectura (Hyland, 2005) y la intencionalidad para tratar de convencer al lector en la recomendación.

\section{Informatividad e intertextualidad}

Las mayores dificultades se presentaron en aspectos relacionados con los estándares de informatividad, correspondiente a los contenidos abordados, e intertextualidad en la relación establecida entre el texto recomendado y el redactado. Los estudiantes acordaron que la recomendación debería "presentar información adecuada: la necesaria, no contar de más, ni el final y mencionar datos sobre la lectura: título, autor y época". Sin embargo, tuvieron dificultades para referirse al texto recomendado y proporcionar información sobre los contenidos y los datos de la lectura. La tabla 1 presenta los elementos de informatividad en el manejo de contenidos de la lectura. En esta y las siguientes tablas indico en paréntesis el número asignado a cada alumno para ubicarlo y tener la posibilidad de dar seguimiento a su desempeño.

Tabla 1. Informatividad: manejo de contenidos

\begin{tabular}{|l|l|l|}
\hline \multicolumn{1}{|c|}{ Elementos de informatividad } & \multicolumn{1}{|c|}{$\begin{array}{c}\text { Primera versión } \\
\text { (número de ocurrencias en los textos) }\end{array}$} & $\begin{array}{c}\text { Segunda versión } \\
\text { (número de ocurrencias en los textos) }\end{array}$ \\
\hline Solo expone contenidos & $8(2,9,10,11,17,21,23,26)$ & $2(23,27)$ \\
\hline Información ajena o imprecisa & $6(3,7,19,24,25,28)$ & $1(19)$ \\
\hline Presenta demasiada información & $2(9,10)$ & $3(24,28,10)$ \\
\hline Información insuficiente & $14(4,5,12,15,16,18,20,22,23$, & $3(15,23,29)$ \\
\hline Referencia ambigua a la lectura & $25,27,29,30,31)$ & $1(11)$ \\
\hline No menciona el libro ni el compilador & $11(2,5,6,12,18,19,20,21,29,31)$ & $17(1 ., 2,5,6,10,12,15,16,19$, \\
\hline Presenta información suficiente & $22(1,3,4,5,7,8,10,11,13,14,15,16$, & $23,24,27,28,29,30,31,32)$ \\
\hline para la comprensión & $17,23.24,25,26,27,28,30,31,32)$ & $14(3,4,7,8,9,13,14,17,18$, \\
\hline
\end{tabular}

La tabla 1 muestra la dificultad en las primeras versiones para aportar la información mínima que requiere el lector. Los alumnos parecieron asumir que el interlocutor conocía la información de la lectura recomendada y que era innecesario proporcionarla. El problema también era establecer relaciones de intertextualidad, puesto que no mencionaban el título del libro y el compilador de los textos, o bien consideraron que el título de un relato correspondía al del libro. Podemos 
advertir que los elementos de informatividad e intertextualidad implican que los alumnos puedan emplear recursos y estrategias para remitirse a la información y los datos de la lectura recomendada. Ruiz y Faria (2012) toma en cuenta esta situación al proponer que existen géneros textuales en los que predominan las marcas de intertextualidad para relacionar el escrito, el texto recomendado o reseñado y los contenidos.

En las segundas versiones se destaca el avance de quienes escribieron información suficiente para la comprensión del lector (14 en segunda versión) y la reducción de quienes solo expusieron contenidos y manejaron información insuficiente, ajena o imprecisa, o únicamente expusieron contenidos, en contraste con el ligero aumento de quienes manejaron demasiada información en la segunda versión. Revisemos los siguientes ejemplos, que manifiestan el avance en la segunda versión.

En el texto 9h, el alumno tuvo problemas para cumplir el acuerdo sobre la ortografía, puesto que no logró corregir errores con el corrector del programa Word. Escribió una primera versión expositiva, sin ningún recurso para recomendar el texto. En la segunda versión atendió los acuerdos al expresar su opinión, tomar en cuenta al lector para tratar de convencerlo y presentar la información necesaria, incluyendo el título del libro y el compilador.

Ejemplo 12: texto 9hPrimera versión

El nacimiento de Huitzilopochtli nos narra la Historia de como fue concevido el Dios tan poderoso que era Huitzilopochtli, como es que sus Hermanos los hijos de Cuatlicue y como Huitzilopochtli logra sobre ponerse al odio de sus hermanos principalmente Coyolxhauhqui acabando con todos ellos y defendiendo a su madre.Segunda versión

El Nacimiento de Huitzilopochtli

¿Te atreverías a matar a alguien de tu sangre?

En esta lectura podemos conocer la historia de Huitzilopochtli, un Dios que se enfrenta al odio de sus hermanos... ¿Crees que pueda matarlos?

Si quieres saber más de esta historia donde ademas podras conocer una parte de la cultura
Mexica, esencial en tu pasado prehispánico, buscala en el libro, "Cantos y cronicas del México antiguo" del autor Miguel Léon Portillo, con el subtítulo del "Ciclo de Quetzalcóatl".

A mí en lo personal me facino la historia ya que me encantó como el personaje principal se sobrepuso a las adversidades del rechazo y el odio por las personas menos imaginables para el.

En el texto 16m, la alumna mostró un desempeño favorable en correcciones gramaticales y ortográficas; solo omitió la acentuación en "satisfacera". En la primera versión empleó referencias textuales ambiguas como "Este texto habla" y "esta lectura me pareció", sin mencionar ninguna información sobre el poema, el autor y la época. En su escrito, los referentes están ausentes o corresponden a elementos extratextuales desconocidos para el lector. En total, tenemos 11 textos con estas características en la primera versión. Al preguntarle a qué texto o contenido se refería, se percató de la falta de información, sin embargo, en su segunda versión no completó las relaciones de intertextualiad al no escribir el título del libro donde aparece el poema ni el compilador. Además, interpretó el "Canto de las mujeres de Chalco" como una práctica de prostitución, situación que no está expresada en el poema. Se destaca el avance en su esfuerzo por tratar de convencer mediante la representación directa para comentar, tomar en cuenta al lector y presentar ejemplos de la lectura.

Ejemplo 13: texto $16 \mathrm{~m}$

Primera versión

Este texto habla de cómo prostituían a las mujeres en el mundo prehispánico, pero eran presentadas como flores hermosas, y a través de esta pequeña conocer un poco de las historias de las mujeres que fueron presentadas a Axayácatl, pero te podrías sentir un poco confundida(o), pero en verdad es bastante interesante.

En lo personal esta lectura me pareció bastante interesante, porque contiene todas las emociones, tristeza, amor, odio, etc. Así que yo te la recomendaría plenamente y aparte es un género de lectura que te aseguro nunca has leído. 


\section{Segunda versión}

El canto de las mujeres de Chalco

El texto fue escrito por Aquiahuatzin de Ayapanco en el siglo XVI.

Este es un texto de tradición oral, usa mucho la metáfora y es un texto con estructura de poema.

Esta lectura se desarrolla en el México Prehispánico durante el gobierno de Axayácatl el cual era gobernador del Imperio Azteca.

En él nos muestran un poco acerca de cómo es que eran "entregadas" a Axcayacatl por ser el gobernador, con este texto podremos conocer a algunas de estas mujeres, y como es que fueron entregadas, o se entregaron al gran gobernador del Imperio Mexica.

¿Acaso tú me has comprado, tú para ti me adquiriste, niñito mío? ¿Tal vez cambiarás mi placer, mi embriaguez?

Acaso desprecias, te has disgustado, pequeño compañero, ya me voy a mi casa, niñito mío."

Con este texto nos podemos percatar que el tema de la "prostitución" existe hace mucho tiempo.
Estoy muy segura que es un texto que te llamará la atención y también que satisfacera tus gustos por la lectura, porque trata un tema interesante y aparte es sobre la cultura antigua de nuestro país.

En general, en la primera versión los estudiantes enfrentaron dificultades al proporcionar información insuficiente, imprecisa o demasiada, o solo exponer contenidos. En todas estas situaciones, las actividades realizadas sirvieron de apoyo para mejorar los escritos.

\section{Representación textual del alumno y de sus interlocutores}

En la perspectiva de Hyland (2005), la representación textual de quien escribe y de los interlocutores constituye una toma de conciencia sobre la intencionalidad comunicativa y, en términos de Ivanič (1998), una forma de construcción de identidad que permite la crítica para recomendar un texto. La tabla 2 muestra la variedad de desempeño en la intencionalidad de cada alumno para representarse como autor, así como a los interlocutores en el texto.

Tabla 2. Representación textual de interlocutores y del alumno como autor

\begin{tabular}{|l|l|l|}
\multicolumn{1}{|c|}{ Tipo de representación textual } & \multicolumn{1}{|c|}{ Primera versión } & \multicolumn{1}{c|}{ Segunda versión } \\
\hline $\begin{array}{l}\text { Sin representación del autor ni } \\
\text { de los interlocutores }\end{array}$ & $5(2,9,11,20,21)$ & $1(21)$ \\
\hline Se representa como autor & $6(4,12,22,24,26,29)$ & $4(20,24,27,29)$ \\
\hline Representa a los interlocutores & $14(1,3,6,7,8,10,13,14$, & $15(1,2,3,6,8,10,11,13,14$, \\
\hline $\begin{array}{l}\text { Se representa como autor y a los } \\
\text { interlocutores para recomendar }\end{array}$ & $15,17,28,30,31,32)$ & $15,17,22,23,28,30)$ \\
\hline
\end{tabular}

Los datos muestran el avance en el desempeño para la representación textual de los estudiantes como autores y de los interlocutores, principalmente en la reducción de quienes solo expusieron los contenidos sin opinar ni aludir al lector y el aumento de quienes se dirigieron a este al tratar de expresar sus puntos de vista o impresiones. Podemos apreciar la incorporación de la información requerida para mejorar textos totalmente expositivos que no aludían a los lectores. Este avance es el resultado de la regulación del desempeño al tomar en consideración los acuerdos para tratar de mejorar la recomendación.

En las segundas versiones, la reducción de la representación textual de los estudiantes y el aumento de la representación de interlocutores evidencian la dificultad para expresar de manera directa los puntos de vista. Estos resultados sugieren que es más sencillo 
llamar la atención del lector que asumir una opinión sobre el contenido. Representar textualmente al lector es un recurso útil para atraer su atención y tomarlo en cuenta, pero no implica que el estudiante logre expresar una opinión. Asimismo, la representación directa del autor en la primera persona del singular tampoco implica emitir una opinión o impresión, por ejemplo, cuando simplemente expresa que el texto le resulta interesante y se limita a exponer el contenido. En el siguiente ejemplo, la alumna trató de representar a los lectores y expresar su opinión. En la primera versión se representó de manera inclusiva al plantear que "podemos disfrutar" y "tenemos la oportunidad", sin embargo, no expresó su opinión. Se percató de ello, y en la segunda versión manifestó su impresión de gusto e interés por el texto en primera persona del singular, con un predominio de la representación de los interlocutores.

\section{Ejemplo 14: texto $18 \mathrm{~h}$}

\section{Primera versión}

"Mucho honraban los mexicas a Huitzilopochtli, sabían ellos que su origen, su principio fue de esta manera..."

El nacimiento de Huitzilopochtli es una historia que ha sido transmitida de forma oral por la gente del pueblo mexica, gracias a ellos podemos disfrutar de este gran relato y saber sobre el origen del Dios Sol.

Todos tenemos la oportunidad de explorar el antiguo México ¿Te animas a leerlo?

\section{Segunda versión}

"Mucho honraban los mexicas a Huitzilopochtli, sabían ellos que su origen, su principio fue de esta manera..."

Este es un fragmento de "El nacimiento de Hutzilopochtli" una lectura que puedes encontrar en el libro recopilatorio "Cantos y crónicas del México antiguo" que es un libro hecho por Miguel León Portilla. Es una leyenda que me gustó mucho y ya que habla de un dios tan importante para muchas otras culturas del mundo, el Dios Sol.

En este cuento podrás encontrar el como la madre de Huitzilopochtli se vio amenazada por sus muchos hijos y sobre todo por su desconsiderada hija; también sabrás que el nacimiento de un Dios puede ser muy emocionante y heroico.

Espero que puedas leerlo y te guste tanto como a mí me ha gustado.

\section{Intencionalidad para tratar de convencer al lector}

Los estudiantes acordaron que quien escribe debe tratar de convencer y motivar a la lectura. La caracterización de la intencionalidad pretende dar cuenta de los recursos textuales de los estudiantes para recomendar la lectura, aun cuando enfrenten dificultades o no logren emplear los recursos requeridos. La tabla 3 presenta la intencionalidad en el manejo de recursos para tratar de convencer a los lectores.

Tabla 3. Intencionalidad para tratar de convencer al lector

\begin{tabular}{|l|l|l|}
\hline \multicolumn{1}{|c|}{ Recursos empleados para tratar de convencer al lector } & \multicolumn{1}{|c|}{ Primera versión } \\
\hline Expone contenidos sin recursos para convencer al lector & $\begin{array}{l}7(2,9,10,11, \\
17,21,26)\end{array}$ & $1(27)$ \\
\hline Intenta convencer mencionando contenidos & $\begin{array}{l}9(1,4,6,7,18, \\
19,25,30,31)\end{array}$ & $3(1,24,30)$ \\
\hline Solo expresa su impresión: me gusta, es interesante & $6(5,15,22,23,29,32)$ & $4(19,21,23,31)$ \\
\hline Expresa su comentario personal del texto & $5(12,20,24,27,28)$ & $3(20,28,29)$ \\
\hline Emplea recursos para tratar de convencer al lector & & $21(2,3,4,5,6,7,8,9$, \\
\hline
\end{tabular}


El avance en la intencionalidad para tratar de convencer al lector es el resultado de tomar en cuenta los acuerdos con la idea de mejorar los textos. Las segundas versiones presentan avance en el desempeño en la reducción de contenidos como recurso único (de 7 a 1) o bien como sustento para intentar convencer (de 9 a 3). La mayoría de alumnos tomó conciencia de que no basta con una impresión del tipo "me gusta" o "es interesante", por ello en la segunda versión expresaron su opinión y se representaron a sí mismos y al lector para tratar de convencerlo. Solo un alumno (texto 23) mantuvo el recurso de expresar su impresión del tipo "me gusta, es interesante" en ambas versiones.

La tabla 3 muestra la dificultad de quienes solo expresan un comentario personal para recomendar la lectura sin desarrollar su idea (5 alumnos en la primera versión). De estos estudiantes, en la segunda versión apenas uno logró representarse a sí mismo y a los lectores para opinar (texto 12). Dos se centraron únicamente en los contenidos (textos 24 y 27) y los otros dos mantuvieron el mismo recurso en la segunda versión (textos 20 y 28). Esta situación evidencia la dificultad para manifestar comentarios sobre los contenidos y tomar en cuenta a los lectores.

Con el propósito presentar evidencias de distintos niveles de desempeño, a continuación presento ejemplos representativos de avances de los alumnos en la intencionalidad al tomar en cuenta los acuerdos, y otros que enfrentaron distintas dificultades.

En el texto 24h, el alumno afrontó el manejo impreciso de la información. En su primera versión considera que Quetzalcóatl "tendrá que enfrentar a los magos y su venganza", que tendrá la oportunidad de "huir de sus problemas" y que fue incitado al alcoholismo. En realidad, en el relato mitológico, Quetzalcóatl nunca enfrentó a los magos y estos lo embriagaron como parte de un hechizo. Además, el alumno cerró con comentarios alejados de la temática del texto: el alcoholismo, el odio, la cobardía y la prevención de problemas actuales. Se representó directamente para expresar su opinión, sin embargo se desvió de la temática del relato. Aludió a "los estudiantes", a quienes recomendó la lectura, pero no representó textualmente a sus lectores para dirigirse a ellos.

Ejemplo 15: texto 24h

Primera versión

La huida de Quetzalcoatl

Este texto de la era preshispánica habla de 3 magos que quieren acabar con el reino de Tula empezando por su rey Quetzalcóatl, los magos incitaran al alcoholismo al rey, crearan desorden y disturbio entre la población.

El rey tendrá que enfrentar a los magos y su vergüenza por salvar a su reino de la muerte y la destrucción. El tendrá oportunidad de como muchos tienen en su vida de huir de sus problemas en lugar de enfrentarlos; por miedo al fracaso y la vergüenza de mostrarse ante los demás después de los ridículos pasados que pueden ocasionar burlas y/o desagrado.

En mi opinión aunque el texto data de una época muy diferente a la nuestra muestra problemas aun vigentes como lo son el odio, el alcoholismo y la cobardía; lo recomiendo para los estudiantes porque ayuda a crear conciencia sobre estos problemas y por lo tanto a prevenirlos.

En la segunda versión, el alumno eliminó los contenidos ajenos y se centró en el relato; sin embargo, contó el final y no proporcionó información sobre el libro donde leyó el texto, ni el autor. Intentó llamar la atención sobre el regreso de Quetzalcóatl, pero esta información no aparece en la lectura. Al final no opinó sobre aspectos concretos de los contenidos, y solo mencionó "su valor histórico y hechos que relata" para "quien quiera leer algo nuevo". Asimismo, podemos observar la dificultad para resolver cuestiones ortográficas y de acentuación, por ejemplo en "prehispánica”, "enbriagan", "uira”, "morirá” y "regresara". En este caso, podemos advertir la omisión en las correcciones correspondientes al procesador de textos.

Segunda versión

La huida de Quetzalcoatl

Este texto de la era prehispanica se origina en la

Ciudad de Tula, la más hermosa. 3 magos quieren 
acabar con la ciudad y con su rey Quetzalcoatl, para esto lo enbriagan, lo expulsan y causan desorden y muerte en su reino. El rey uira y su gente morira esperando su regreso ¿¿regresara?

Yo recomiendo esta lectura por su valor histórico y los hechos que relata así que es altamente recomendable para quien quiera leer algo nuevo.

En la primera versión del texto $7 \mathrm{~m}$, la alumna proporcionó información insuficiente sobre la lectura. El ejemplo que utiliza y su pregunta final no le ayudaron a resolver esta problemática. Tampoco expresó una opinión, ni se representó textualmente como autora.

Ejemplo 16: texto $7 \mathrm{~m}$

\section{Primera versión}

El lenguaje de Zuyua proviene de la literatura Maya.

Narra el proceso que deben seguir los Batabes (aspirantes a gobernadores).

No es una tarea fácil, pues es por medio de acertijos

"Hijo mío, traéme una vieja que cuide milpas, que tenga el cuerpo negro y las nalgas de siete palmos; tengo deseos de mirarla."

...¿QQué llevarías a los Halach Uiniques?...

En la segunda versión proporcionó parcialmente la información requerida; confundió el texto colonial con uno prehispánico y, a pesar de tener autor, lo consideró anónimo. Su pregunta inicial le ayudó a dirigirse a sus interlocutores y el ejemplo de la lectura se relaciona con la información proporcionada. Intentó atraer al lector anticipando la respuesta en "!Noi, no pienses mal” y retomó el contenido de su recomendación en "ahora sí, ¿qué llevarías a los jefes?”. Su opinión al final del texto le sirvió para destacar el interés sobre los acertijos y motivar a la lectura. Su desempeño se caracteriza por una revisión y reflexión crítica conforme a los acuerdos para mejorar el escrito.

Segunda versión

El lenguaje de Zuyua
¿Te interesa saber sobre los Mayas?... el Lenguaje de Zuyua es una literatura maya prehispánica el cual su autor es anónimo.

Este texto te va a explicar el proceso de selección de los Batabes (son los aspirantes a ser gobernadores del pueblo maya). Hombres con mucha valentía, astucia o inteligencia, pues tendrán que enfrentarse a los acertijos de los reyes, los Halach Uiniques.

Por ejemplo. "hijo mío, traéme aquí una vieja que cuide milpas, que tenga el cuerpo negro y las nalgas de siete palmos; tengo deseos de mirarla".

!No $;$, no pienses mal, pues los acertijos son relacionados con la comida... ahora sí, ¿qué llevarías a los jefes?

...una última cosa: en mi opinión, yo lo pensaría dos veces para formar parte de los batabes, pues sabes qué es lo que piden, le atinas, o simplemente mueres...

Te aseguro que te va a gustar la lectura y no la vas a soltar hasta que termines de leerla.

En el texto 5h, el alumno presentó dificultades en la corrección de la acentuación. En la primera versión no incorporó información sobre la lectura: contenido, época, libro donde aparece el relato y el compilador. Para ayudarlo a resolver la referencia ambigua inicial sobre los personajes, le pregunté: “iquiénes tenían una rigurosa educación?", y le comenté la necesidad de escribir la información completa. Se representó textualmente para expresar su opinión sobre el estilo, el léxico, los significados y la estructuración. Le sugerí que también motivara a quienes tienen otros gustos y que proporcionara ejemplos de la lectura.

Ejemplo 17: texto 5h

\section{Primera versión}

\section{Nacimiento del Sol Hutzilopochtli}

El texto es muy interesante ya que se puede apreciar que tenían una rigurosa educación y por tanto una mejor redacción y cuidadoso estilo de escritura del texto.

Particularmente me gusta el estilo ritmico con el que sostienen el texto, palabras diferentes pero que a la vez siguen teniendo el mismo significado y con el afán o meta de hacerlas rimar. Oraciones que se repiten de forma en que lo asimiles como si 
fuera el coro y esto a su vez hace que el texto tenga un estilo armónico y no te aburras de la lectura.

Particularmente me gustan las historias de los Dioses prehispanicos y el hecho en que me hayan dado a leer el texto hace que disfrute más de la lectura sí que si tienes gustos parecidos en cuanto al tipo de lectura te invito a leerlo

En la segunda versión incorporó la información requerida, sin embargo, no escribió datos del libro ni del compilador. Su representación inclusiva, involucrando a sus interlocutores, en combinación con sus preguntas le ayudaron a atraer la atención del lector y provocar el interés sobre el relato: “Todos sabemos lo majestuosos que son los dioses pero, ¿Sabes como nace uno?”. A pesar de no representarse textualmente para expresar una opinión, ni presentar ejemplos, el manejo de la información permite que el lector pueda interesarse en el relato. El alumno decidió centrarse en el contenido y eliminar sus comentarios de la primera versión sobre el estilo, el manejo del léxico, los significados y la estructuración, a pesar de que le daban variedad y riqueza a su recomendación.

Segunda versión

Nacimiento del Sol Huitzilopochtli

Todos sabemos lo majestuosos que son los dioses pero, ¿Sabes como nace uno?

Nos remontamos a la epoca de los Mexicas que mucho honraban a Huitzilopochtli, y a otros dioses. Una de ellas fue Cuatlicue, la Diosa madre de los surianos que al magicamente embarazarse sufrirá una traición de quien menos lo pensaba. ¿Quienes seran los inleales?

¿Quién podrá defenderla?

Huitzilopochtli viene al mundo con toda su furia a vengar a su madre con un poder inigualable.

Te invito a conocer esta gran historia del nacimiento en donde alguien llamado Coyolxauhqui estara poniendo todo en contra de Coatlicue y huitzilopochtli para vencerlos.

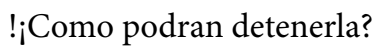

La revisión de ejemplos de distinto nivel de desempeño nos permite caracterizar la intencionalidad en el manejo de recursos para tratar de convencer al lector y contemplar que las experiencias de revisión y edición de los textos a partir de los acuerdos tomados son útiles para la reflexión, la valoración y la autorregulación de la redacción. Asimismo, las dificultades no resueltas en las versiones redactadas nos permiten contemplar la necesidad de un desarrollo gradual de prácticas y hábitos, por ejemplo en la corrección ortográfica y de acentuación mediante el corrector del procesador de textos Microsoft Word.

\section{Conclusiones}

La aplicación del diseño de actividades para favorecer la redacción de recomendaciones de textos narrativos aporta cuestiones de interés en aspectos metodológicos y del desempeño de los estudiantes. Los resultados en las primeras versiones muestran que estos requieren un proceso continuo de práctica y retroalimentación para aprender a tomar en cuenta las experiencias en las actividades realizadas, con la idea de desarrollar la redacción de este tipo de escritos. Aprender a autorregular el desempeño en la revisión y edición para tratar de mejorar las segundas versiones implica la toma de conciencia gradual de los recursos de textualización, los acuerdos tomados y la valoración del desempeño propio y de otros.

Las actividades previas a la redacción de las recomendaciones facilitaron la sensibilización sobre los estándares de textualidad, la revisión de distintos niveles de desempeño y la socialización de los acuerdos, como guías rectoras y orientaciones surgidas de la interacción con los estudiantes, para evitar así imposiciones ajenas y descontextualizadas. Sin embargo, no basta el manejo de conocimientos y criterios de textualidad; en la práctica cotidiana y retroalimentada de revisión y edición es donde se manifiesta el avance gradual en la intencionalidad y en la autorregulación del desempeño. Por ello, a pesar de que los estudiantes conocían los acuerdos tomados, fue necesario retomarlos constantemente como el sustento para lograr la autorregulación en las decisiones de textualización. Esta consideración es fundamental en cualquier diseño y propuesta de actividades de escritura. 
Los resultados muestran que los estudiantes requieren experimentar y autorregular gradualmente los conocimientos y acuerdos socializados sobre criterios de textualización. Es necesario propiciar la reflexión sobre el desempeño en términos de los estándares de textualidad, los acuerdos alcanzados, la representación textual del autor y los interlocutores y los intentos por tratar de convencer a los lectores. Es fundamental tomar en cuenta las principales dificultades afrontadas por los estudiantes: la identificación del género textual requerido para recomendar, el manejo de los contenidos, correspondientes al estándar de informativivdad, y el establecimiento de relaciones de intertextualidad entre el texto redactado y la lectura realizada. En estos aspectos, los estudiantes manifestaron la multiplicidad de prácticas de autorregulación y valoración del desempeño en la revisión y edición de los escritos.

Podemos establecer que la búsqueda de soluciones a las dificultades afrontadas les permite a los estudiantes avanzar en el desempeño y abordar aspectos relacionados con su representación textual y la de los interlocutores, así como experimentar distintos recursos para tratar de convencer a los lectores. Asimismo, requieren práctica para recibir retroalimentación mediante las sugerencias recibidas y para el manejo contextualizado del corrector ortográfico y gramatical de Word. En cuanto a la revisión y valoración del desempeño, los resultados ponen de manifiesto la mayor facilidad para evaluar los comentarios redactados por estudiantes anónimos, pero las dificultades para aplicar los criterios de evaluación a su propio desempeño. Por ello, es necesaria la práctica para identificar las características del texto redactado, y asumir una actitud objetiva al considerar los acuerdos para evaluar el desempeño propio y el de otros.

En la toma de conciencia del desempeño propio está presente el impacto y lo que significa para los estudiantes recibir sugerencias y autoevaluar sus escritos como parte de la construcción de identidad en la escritura. Las actividades de retroalimentación permitieron que valoraran las observaciones $y$ sugerencias $y$, de manera reflexiva, tomaran decisiones encaminadas a resolver las dificultades para asumir una opinión o impresión de la lectura $\mathrm{y}$ tomar en cuenta a los interlocutores. El avance en la intencionalidad y el desempeño se logra cuando los estudiantes asumen, como autores, sus puntos de vista o impresiones sobre la lectura, al establecer las relaciones de informatividad e intertextualidad, mediante diversos recursos para comentar la lectura seleccionada. De este modo, el posicionamiento textual de los estudiantes como autores constituye la base de la construcción de identidad en las prácticas de textualidad.

Las decisiones metodológicas en la aplicación de las actividades aportan el enfoque de la retroalimentación reflexiva para propiciar la autorregulación en la revisión y edición de los textos, al contemplar y retomar constantemente las experiencias, los aprendizajes de textualización y los acuerdos sobre los textos. La metodología para caracterizar los escritos mediante categorías en términos de estándares de textualidad permite apreciar de manera objetiva el desempeño en las versiones redactadas. La consideración de elementos de informatividad resultó fundamental por tratarse de la principal dificultad y, además, facilitó contemplar las relaciones de referencia e intertextualidad con el texto recomendado.

Los criterios sobre representación textual del estudiante como autor y del lector nos permiten apreciar la reflexividad sobre la construcción de recursos de textualidad y de identidad como elementos constitutivos del tipo de texto requerido. Las categorías de caracterización sobre los recursos para tratar de convencer a los lectores nos permiten valorar la intencionalidad de los estudiantes, por ejemplo, quienes expresan una impresión y para sustentarla solo exponen contenidos. En estos casos, lo relevante es la caracterización objetiva del desempeño y de los intentos en las decisiones de revisión y edición, por ejemplo, al incorporar, los contenidos pertinentes, la opinión y la representación textual del estudiante y el lector.

Finalmente, la aplicación de las actividades para fomentar la redacción de recomendaciones de lecturas posibilita a los estudiantes la conformación de un acervo de diversas experiencias, conocimientos, referentes sobre distintos desempeños y prácticas 
de revisión y edición textual. Estas pueden ser de utilidad en un diseño metodológico que propicie la valoración y la autorregulación reflexiva del desempeño en las prácticas de escritura.

\section{Referencias}

Adam, J. M. (2004). Linguistique textuelle. Des genres de discours aux textes. Une introduction méthodique á l'analyse textuelle des discours. París: Nathan.

Bajtín, M. (1982). El problema de los géneros discursivos. En Estética de la creación verbal. México: Siglo xxI.

Barrera-Vázquez, A. y Rendón, S. (eds.) (1983). Libro de los libros de Chilam Balam. México: Fondo de Cultura Económica.

Bausela-Herreras, E. (2007). Relación entre autorregulación y autoconocimiento de la escritura con la coherencia y productividad de un texto. Cuestiones pedagógicas, 18: 257-270.

Beuchot, M. (2015). Elementos esenciales de una hermenéutica analógica. Diánoia, 60(74): 127-145.

Birembaum, M. (2002). Assessing self-directed active learning in primary schools. Assessment in Education: Principles, Policy and Practice, 9(1): 119-138.

Brockett, R. G. y Hiemstra, R. (1991). Self-Direction in Adult Learning. Perspectives on theory, research and practice. Londres: Routledge.

Camps, D. (2009). Advanced EFL students' revision practices through their writing process. En A. Cater, T. Lillis y S. Parkin (coords.). Why writing matters: Issues of access and identity in writing research and pedagogy (pp. 129-149). Ámsterdam: John Benjamins Publishing.

Carlino, P. (2004). El proceso de escritura académica. Cuatro dificultades de la enseñanza universitaria. Educere, 8(26): 321-327.

Castelló, M., Bañalez-Faz, G. y Vega-López, N. A. (2010). Enfoques en la investigación de la regulación de escritura académica: estado de la cuestión. Electronic Journal of Research in Educational Psychology. 8(3): 1253-1282.

Charadeau, P. (2004). La problemática de los géneros. De la situación a la construcción textual. Signos, 37(56): 23-39. Disponible en: http://dx.doi.org/10.4067/ S0718-09342004005600003

http://www.scielo.cl/scielo.php?pid=S071809342004005600003\&script=sci_arttext
Ciapuscio, G. E. (2015). La noción de género en la lingüística sistémico-funcional y en la lingüística textual. Signos, 38(57): 31-48. Disponible en: http://www. scielo.cl/scielo.php?script=sci_arttext\&pid=S071809342005000100003\&lng=en \&nrm=iso http:// dx.doi.org/10.4067/S0718-09342005000100003

De Beugrande, R. y Dressler, W. (1997). Introducción a la lingüística del texto. Barcelona: Ariel Lingüística.

Dickinson, L. (1987). Self-instruction in language learning. Malta: Cambridge University Press.

Eggins, S. y Martin, J. R. (2003). El contexto con género: una perspectiva lingüística funcional. Signos, 36(54): 185-205. Disponible en: http://dx.doi.org/10.4067/ S0718-09342003005400005

http://www.scielo.cl/scielo.php?pid=S071809342003005400005\&script=sci_arttext

Hernández-Rodríguez, E. (2015). Prácticas y concepciones de alumnos bachilleres al escribir comentarios de textos narrativos. CPU-e Revista de Investigación Educativa, 21(2): 232-253.

Hyland, K. (2005). Metadiscourse: Exploring interaction in writing. Londres: Continuum.

Ivanič, R. (1998). Writing and identity: The discoursal construction of identity in academic writing. Filadelfia: John Benjamins Publishing Company.

Knowles, M. S. (1975). Self-directed learning: A guide for learners and teachers. Nueva York: Cambridge Book Company.

León-Portilla, M. (2003). Cantos y crónicas del México Antiguo. México: Promo Libro.

Martín Leralta. S. (2006). La integración de la competencia estratégica en el currículo de lengua extranjera. ELUA 20: 233-257

Oxford, R. (1990). Language learning strategies: What every teacher should know. Boston: Heinle \& Heinle/ Cengage.

Palapanidí. K. (2016). La enseñanza de las estrategias compensatorias. Revista Nebrija de Lingüística Aplicada 10 (2). artículo 5. Disponible en: http://www.nebrija. com/revista-linguistica/la-ense\%C3\%Blanza-de-lasestrategias-compensatorias

Perrault. Ch. (2006). Cuentos de Perrault, edición de Rafael Penagos. Madrid: Real de Catorce.

Ruiz, E. M. S. D. y Faria, M. B. (2012). A intertextualidade no genero reseña. Linguagem em (Dis)curso,

Torre-Puente, J. (1992). Aprender a pensar y pensar para aprender. Madrid: Narcea. 
Van Dijk, T. A. (1983). La ciencia del texto. México: Paidós.

Wenden, A. (1986). Helping language learners think about learning. ELT Journal. An international journal for teachers of English to speakers of other languages. 40(1): 161-175.
Zavala, V. (2009). La literacidad o lo que la gente hace con la lectura y la escritura. En D. Cassany (comp.). Para ser letrados. Voces y miradas sobre la lectura. Barcelona: Paidós.

Para citar este artículo

Hernández-Rodríguez, E. (2018). Experiencia de redacción autorregulada y retroalimentada en la recomendación de textos literarios en bachillerato. Folios, 47, 99-117.

\section{Anexo 1}

"El nacimiento de Huizilopochtli" relata el enfrentamiento de este dios con Coyolxauhqui y sus demás hermanos, quienes intentan matar a su madre, Coatlicue, por haber quedado embarazada. Huitzilopochtli recibe la ayuda de uno de sus hermanos desde el seno materno y al nacer, mata a Coyolxauhqui y a sus demás hermanos. "La huida de Quetzalcóatl” narra el recorrido y acciones realizadas por este rey después de sufrir las consecuencias de las trampas y hechizos de Tezcatlipoca para destruir su reino y obligarlo a abandonar su pueblo. "La ruina definitiva de Tula" relata la forma en que Tezcatlipoca provoca que se enfrenten y lleguen a su destrucción total los pueblos que abandonó Quetzalcóatl. El “Canto de las mujeres de Chalco" presenta las actitudes de una o más mujeres, representadas como flores, quienes dan placer sexual al señor Axáyacatl. El poema "Alegraos" del poeta Nezahualcóyotl alude a una actitud de regocijo ante la experiencia de la vida. "El lenguaje de Zuyua" (Barrera-Vázquez y Rendón, 1983) es un documento colonial para explicar un ritual de acertijos, relacionados con la comida, para determinar la sucesión de los gobernantes mayas. Los aspirantes que respondían correctamente accedían al trono y los que fallaban recibían fuertes castigos. Los estudiantes destacaron el interés por lo prehispánico, los personajes, dar a conocer los dioses, el estilo del lenguaje, la belleza de los mitos y los sentimientos. La mayoría eligió "El nacimiento de Huitzilopochtli" (24), los demás seleccionaron la "Huida de Quetzalcóatl" (3), "La ruina definitiva de Tula" (1), "El lenguaje de Zuyua" (1), "Las mujeres de Chalco" (2) y el poema "Alegraos" de Nezahualcóyotl (1).

\section{Anexo 2}

Recomendación 1 del texto de Perrault

¿Cómo te imaginas a la bella durmiente que tenga como pariente a una ogra y que su hijo sea el amor de tu vida?

Esta historia es escrita por el francés Charles Perrault en la época del Neoclásico, en esta historia al principio se describe la casi amargura de que los reyes no tengan a un hijo, pero finalmente la reina da a luz de una hermosa niña.

¿Pero que pasara después de su gran bautizo que le organizaron sus papás?

En esta gran historia de magia y fantasía se desata la gran maldad en el reino pero sobre todo en el castillo, al final de todo esto hay paz y felicidad como todos la conocemos.

Mi recomendación es que la lean y que no se imaginen la historia que todos conocemos habitualmente.

Mi comentario es que apoyo esta historia porque en el desarrollo y desenlace de la historia se pone lo más interesante.

¿Y tú qué harías si te comiera tu suegra?

\section{Anexo 3.}

\section{Recomendación 2 del texto de Perrault}

La Bella Durmiente del bosque Me parece una historia muy entretenida, en donde encontrarás resentimiento, amor, odio, me gustó porque una no se aburre a lo largo de la lectura, está muy bien como la princesa y el príncipe siguen con su amor.

Lo recomiendo ya que está divertida y muy interesante y creo que les podría gustar, no está aburrida. 